\title{
CO-aVoID: coronavirus outbreak affecting variability of presentations to a local emergency department
}

\author{
Valancy Cole ${ }^{1}$ Paul Atkinson ${ }^{1,2,3} \cdot$ Robert Hanlon $^{1} \cdot$ Daniel J. Dutton ${ }^{4} \cdot$ Tong Liu $^{4} \cdot$ Jacqueline Fraser $^{3}$. \\ David Lewis $^{2,3} \cdot$ Keith R. Brunt ${ }^{1} \cdot$ Hana Wiemer $^{5} \cdot$ Tara Dahn $^{5}$ - Patrick T. Fok ${ }^{5} \cdot$ Chris Vaillancourt $^{2,3}$
}

Received: 12 June 2020 / Accepted: 15 October 2020 / Published online: 4 January 2021

(c) Canadian Association of Emergency Physicians (CAEP)/ Association Canadienne de Médecine d'Urgence (ACMU) 2021

\begin{abstract}
Background The impact of the COVID-19 pandemic on public health, specifically on patients presenting to the emergency department (ED) with non-COVID-related diseases, remains largely undocumented.

Objective This study explored how overall rates of presentations to the emergency department were impacted immediately after the declaration of the COVID-19 pandemic, and specifically how key presenting symptoms representing emergency, standard and low-acuity conditions were impacted.

Methods A sequential modified Delphi survey and cross-sectional analysis of administrative census data from a tertiary care center in New Brunswick, Canada, were performed. Details of ED presentations for emergency, standard and low-acuity conditions from February 1 to April 30, 2020, were compared to data from previous years.

Results There was a significant decrease in the number of patients visiting the ED with emergency, standard and low-acuity complaints immediately after March 13, 2020, compared to 2019. The proportion of females and males remained similar, with a median age of 48 years in 2020 and 44 years in 2019. Total presentation patterns to the ED (registrations, admissions to hospital and left without being seen numbers) decreased, compared to previous years.

Conclusions We report a predictable decrease in patient visits to the ED with minor, non-life-threatening conditions during a pandemic. However, we also report a decrease in presentations for emergency and standard conditions. Improved messaging highlighting the need to seek help for "true" emergencies, while providing non-ED options for minor, non-life-threatening conditions, may be helpful under normal circumstances and during future pandemics.
\end{abstract}

Keywords COVID-19 $\cdot$ Pandemic $\cdot$ Emergency department

Electronic supplementary material The online version of this article (https://doi.org/10.1007/s43678-020-00036-0) contains supplementary material, which is available to authorized users.

Paul Atkinson

paul.atkinson@dal.ca

1 Dalhousie Medicine New Brunswick, Saint John, NB, Canada

2 Department of Emergency Medicine, Dalhousie University, 400 University Avenue, Saint John, NB E2L 4L2, Canada

3 Department of Emergency Medicine, Horizon Health Network, Saint John, NB, Canada

4 Department of Community Health and Epidemiology, Dalhousie University, Saint John, Canada

5 Department of Emergency Medicine, Dalhousie University, Halifax, NS, Canada 


\section{Résumé}

Contexte L'impact de la pandémie COVID-19 sur la santé publique, en particulier sur les patients se présentant aux services d'urgence (SU) avec des maladies non liées à la COVID, demeure en grande partie non documenté.

Objectif Cette étude a exploré la façon dont les taux globaux de présentations au service des urgences ont été touchés immédiatement après la déclaration de la pandémie de COVID-19, et plus particulièrement la façon dont les principaux symptômes représentant des conditions d'urgence, standard et de faible acuité ont été touchés.

Méthodes Une enquête Delphi séquentielle modifiée et une analyse transversale des données du recensement administratif provenant d'un centre de soins tertiaires du Nouveau-Brunswick, au Canada, ont été réalisées. Les détails des présentations du SU pour les conditions d'urgence, standard et de faible acuité du 1er février au 30 avril 2020 ont été comparés aux données des années précédentes.

Résultats Il y a eu une diminution significative du nombre de patients se rendant au service d'urgence avec des plaintes d'urgence, standard et de faible gravité immédiatement après le 13 mars 2020, par rapport à 2019. La proportion de femmes et d'hommes est demeurée semblable, avec un âge médian de 48 ans en 2020 et de 44 ans en 2019. Le nombre total de modèles de présentation à l'urgence (inscriptions, admissions à l'hôpital et nombre laissé sans être vu) a diminué par rapport aux années précédentes.

Conclusions Nous faisons état d'une diminution prévisible des visites de patients aux urgences pour des affections mineures qui ne mettent pas leur vie en danger pendant une pandémie. Toutefois, nous signalons également une diminution des présentations pour les situations d'urgence et les conditions normales. Des messages améliorés soulignant la nécessité de demander de l'aide pour les urgences « réelles », tout en offrant des options non urgentes pour des conditions mineures et qui ne mettent pas la vie en danger peuvent être utiles dans des circonstances normales et lors de futures pandémies.

\section{Clinician's capsule}

What is known about the topic?

The impact of the COVID-19 pandemic on presentations to the emergency department (ED) with non-COVID related diseases has not been fully documented.

What did the study ask?

Did the total number of ED patients and the type of presenting symptoms change after the declaration of the COVID-19 pandemic?

\section{What did this study find?}

Reductions in rates of presentations were seen for lowacuity, standard, and emergency conditions during the early months of the COVID-19 pandemic.

Why does this study matter to clinicians?

This study identified the need to educate the public surrounding the appropriate use of EDs in both normal circumstances and during future pandemics.

\section{Introduction}

In early 2019, a novel coronavirus, SARS-CoV-2, caused an outbreak of respiratory illness across the world, later termed COVID-19. The outbreak spread globally, and on March 11, 2020, the World Health Organization declared COVID-19 as a pandemic. At that time, there were 118,000 cases in 114 countries, with 4291 deaths as a result of overwhelming pulmonary infections [1] As of June 10, 2020, there were over 7 million cases worldwide and 413372 deaths [2]. Fear of contracting COVID-19 initially resulted in the public being hesitant to seek essential care in emergency departments (EDs) [3]. A recent study reported that a number of patients with myocardial infarctions delayed seeking medical care because of fear of going to the hospital during the pandemic [4].

This study characterizes the changes in ED presentations that occurred during the early stages of the COVID-19 pandemic, specifically the change in ED presentation patterns for selected emergency, standard and low-acuity conditions, as well as total presentations of patients, in a Canadian province that had relatively few confirmed cases of COVID.

\section{Methods}

A sequential modified Delphi survey and cross-sectional analysis of ED census data, from a large tertiary hospital ED in New Brunswick (NB), Canada, were completed. The study used ED census data to analyze the impact of the COVID-19 pandemic on all visits to the ED, as well as "emergency," "standard" and "low-acuity" presenting complaints to the ED.

An initial list of presenting complaints was generated using an ED 5-year admissions database (2015-2019). Selected presenting complaints in all three acuity categories were chosen from that list by a modified Delphi process involving a panel of experts. Surveys were conducted in rounds, and after each round, the responses were collated 
and fed back to the experts until a consensus of $80 \%$ agreement was reached [5-8]. In our study, the modified Delphi consensus survey was distributed to experienced ED clinicians and conducted in three rounds. An electronic query of the ED census data was then performed to ascertain differences in total patient presentation patterns, as well as patients presenting with the final selection of emergency, standard and low-acuity conditions. The data were collected from February 1 to April 30, 2020, and for the same time period in the preceding year (2019), as a control for the typical baseline presentations seen during this season at the ED. Additional data from 2018, 2017 and 2016 were retrieved for certain criteria pertaining to total patient presentation patterns.

We analyzed registrations and admissions using a linear regression model, with each day counted as an observation. Our model adjusted for year $(2019=0,2020=1)$, pre- or post-March 13 (pre $=0$, post $=1$ ), and their interaction (indicating post-March 13, 2020, average registrations or admissions). As such, the coefficient on the interaction was the effect of the pandemic on registrations or admissions, sometimes called the "difference-in-differences" estimator. We also included a control variable for day of the year to adjust for the temporal trends (e.g., holiday-related admissions). The regression equation used was:

$$
\begin{aligned}
\text { ED Use Variable }= & \beta_{0}+\beta_{1} \text { Year }+\beta_{2} \text { Post }- \text { March13 } \\
& +\beta_{3} \text { Interaction }+\beta_{4} \text { Day Of Year }
\end{aligned}
$$

We reported the change as average per-week changes for easier interpretation (multiplying the average per-day changes by seven). Changes in visits per week were then compared to baseline in 2019 to calculate percentage changes. When the baseline in 2020 was meaningfully different from 2019, we used the 2020 value (applicable to bite, constipation, earache, hypertension, rash, urinary tract infection). (Further details of study design and analysis are provided in Appendix Table 1, Table 2, Table 3 and Appendix 2). The study protocol was approved by the Horizon Health Network Research Ethics Board (File number 100902).

\section{Site characteristics}

The study was completed in a tertiary hospital, with an annual ED census of 60,000 patients and an admission rate of $15 \%$. The incidence of COVID-19 in Atlantic Canada, and specifically in New Brunswick, was low during the initial months of the pandemic [9] New Brunswick only had 11 confirmed cases on March 19, 2020, when the Provincial State of Emergency was declared, and as of June 9, 2020, the total number of confirmed cases in the province was 147 with 1 death [10].

\section{Results}

The total number of visits to the ED decreased during the early months of the pandemic, most notably after March 13, 2020, a few days after the World Health Organization declared COVID-19 as a pandemic. Total visits before and after March 13 were 4146 and 3047 in 2020, compared to 4277 and 5451 in 2019. Total admissions before and after March 13 were 608 and 582 in 2020, compared to 657 and 805 in 2019. Data collected between February 1 to April 30, 2020, showed that ED registrations and admissions were lower when compared to the same time period in 2019 , 2018, 2017 and 2016. Total ED registrations were 14976 in the 2019 window, and 11317 in the 2020 window, decreasing by $24.4 \%$. Total admissions and left without being seen (LWBS) numbers also decreased (Appendix Table 4).

Rates of ED presentation for the selected emergency, standard and low-acuity conditions decreased significantly after March 13, 2020. The total number of visits for the selected emergency, standard and low-acuity visits during the pandemic was 2555,1121 and 3517 , compared to 3068,1692 and 4968 during the same time period in 2019 , respectively. On average, this represented a weekly decrease of -61.3 (CI $-85.4,-37.2)$ or $24.3 \%$ in emergency, -158.3 (CI $-189.99,-126.7)$ or $40.9 \%$ in standard and -85.7 (CI $-103.3,-68.1$ ) or $79.3 \%$ in low-acuity visits. Emergency admissions numbers decreased by 12.04 (CI - 22.99, - 1.1) and standard admissions decreased by 10.9 (CI $-21.04,-0.69)$ per week. The following selected presenting complaints were less likely to be seen during the pandemic: abdominal pain, anxiety or situational crisis, back pain, constipation, depression or suicidal, earache, eye pain, fever, general weakness, hypertension, headache, laceration or puncture, nausea and/or vomiting, palpitations or irregular heart rate, rash, sore throat, urinary tract infection. Only cardiac arrest, seizures, urinary retention and weakness or cerebral vascular accident failed to decrease in frequency of presentation (Appendix Table 5, Table 6 and Fig. 1). Age and gender characteristics were similar.

\section{Discussion}

The COVID-19 pandemic is one of the most serious public health crises in recent times. However, its hidden impact on overall public health, specifically on other (non-COVID) diseases, remains unknown. Delays in seeking medical attention for critical illness may result in increased morbidity and mortality, resulting in future increased strain on services.

Our findings show that ED presentations fell significantly across the spectrum of severity during the early stages of the COVID-19 pandemic in a Canadian province 

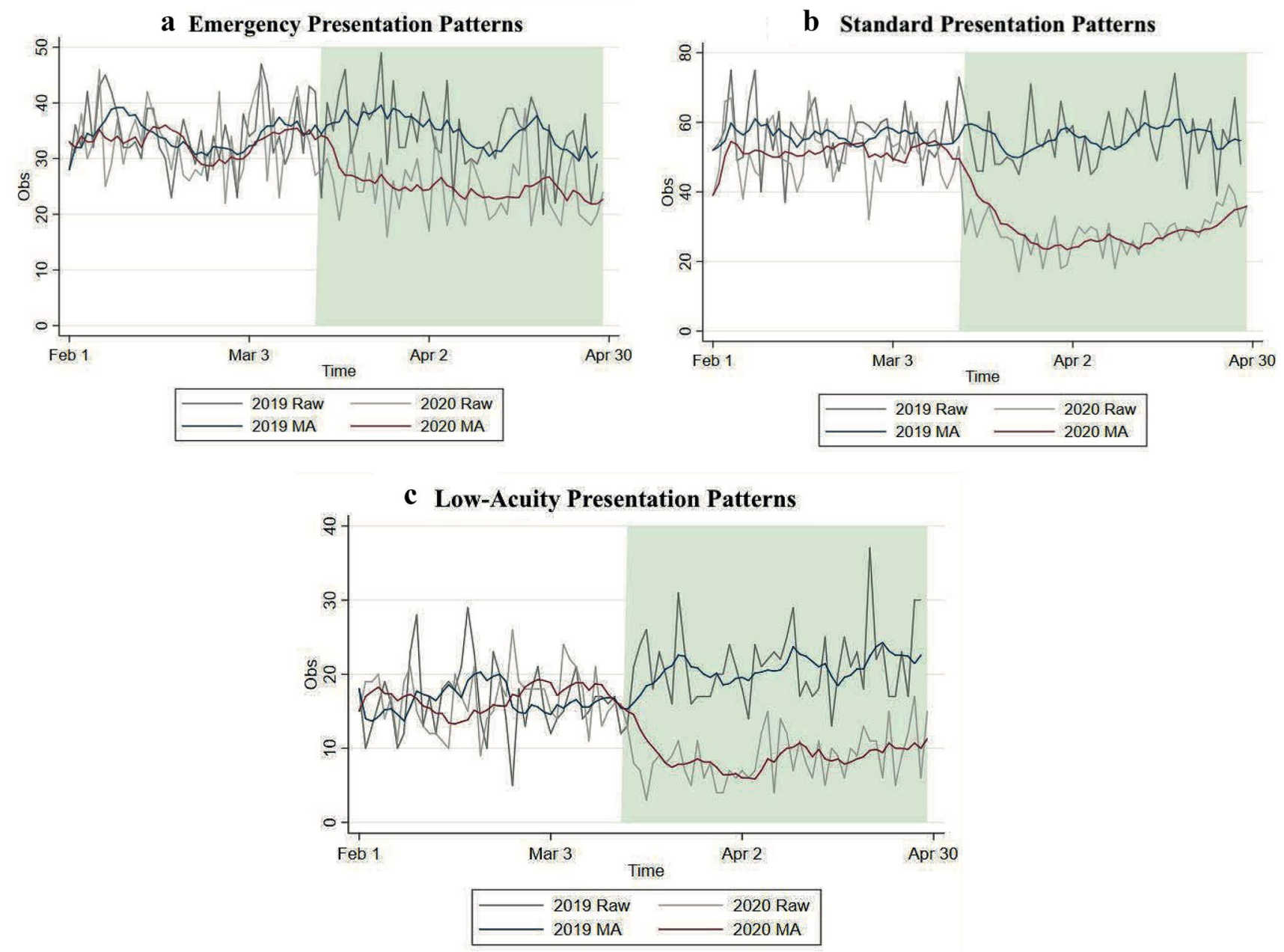

Fig. 1 Emergency Department Presentation trends for selected emergency (a), standard (b) and low-acuity (c) presentations for a threemonth window, immediately before and during the initial phases of the 2020 COVID-19 pandemic, compared with 2019 data, for a tertiary center in New Brunswick, Canada. ("2020 Raw" and "2019
Raw" gray lines indicate the daily raw data. "2019 MA" blue line and "2020 MA" red line represent 7-day moving averages. The green, shaded area indicates declaration of the State of Emergency commencing March 13, 2020.)

weakness, or did patients avoid visiting the ED when they experienced symptoms that would have led them there prior to the pandemic?

Another interesting finding is that left without being seen rate decreased during the pandemic. This could reflect the ED's capacity to cope with a lower, more manageable rate of presentations, despite increased distancing and requirement for infectious disease controls. This study could assist future research examining methods to reduce inappropriate ED visits, which may impact wait-times and overcrowding [12], and assist in better public information messaging.

The study has several limitations including subjectivity to the final list of presenting complaints, the use of census data, relying on a single site, not measuring the actual outcomes for presentations, or identifying where patients may have sought medical attention other than the ED. 


\section{Conclusion}

During the early months of the COVID-19 pandemic in a setting of low incidence for the novel coronavirus, ED presentations decreased in general, including presentations categorized as emergency, standard and low acuity. Public communication strategies are needed to ensure those with potentially serious emergency conditions seek appropriate ED attention, while those with minor, non-life-threatening conditions are directed elsewhere.

Acknowledgements The authors would like to thank the Saint John Regional Hospital Foundation and the New Brunswick Innovation Foundation for unrestricted grants for this research project.

\section{Compliance with ethical standards}

Conflict of interest The authors state no conflict of interest and have received no payment in preparation of this manuscript.

\section{References}

1. World Health Organization. WHO Director-General's opening remarks at the media briefing on COVID-19 [press release]; 2020 March 11[cited 2020 June 11]. Available from: https://www.who. $\mathrm{int} / \mathrm{dg} / \mathrm{speeches} /$ detail/who-director-general-s-opening-remar ks- at-the-media-briefing-on-covid-19-11-march-2020

2. World Health Organization. World Health Organization [internet]. Coronavirus diseases (COVID-19) outbreak situation; 2020 June 10 [cited 2020 June 11]. Available from: https://www.who.int/ emergencies/diseases/novel-coronavirus-2019
3. Thornton J. Covid-19: A and E visits in England fall by $25 \%$ in week after lockdown. BMJ. 2020;369:m1401.

4. Tam C-CF, Cheung K-S, Lam S, Wong A, Yung A, Sze M, et al. Impact of coronavirus disease 2019 (COVID-19) outbreak on ST-segment-elevation myocardial infarction care in Hong Kong China. Circ Cardiovasc Quality Outcomes. 2020;13(4):006631.

5. McKenna HP. The Delphi technique: a worthwhile research approach for nursing? J Adv Nurs. 1994;19(6):1221-5.

6. Diamond IR, Grant RC, Feldman BM, Pencharz PB, Ling SC, Moore AM, et al. Defining consensus: a systematic review recommends methodologic criteria for reporting of Delphi studies. J Clin Epidemiol. 2014;67(4):401-9.

7. Caroff SN, Citrome L, Meyer J, Sajatovic M, Goldberg JF, Jain $\mathrm{R}$, et al. A modified Delphi consensus study of the screening, diagnosis, and treatment of tardive dyskinesia. J Clin Psychiatry. 2020;81(2): 12983 ((19cs)).

8. Shepherd V, Wood F, Hood K. Establishing a set of research priorities in care homes for older people in the UK: a modified Delphi consensus study with care home staff. Age Ageing. 2017;46(2):284-90

9. Government of Canada. Government of Canada [internet]. Coronavirus disease (COVID-19): outbreak update; 2020 June 10 [cited 2020 June 11]. Available from:https://www.canada.ca/en/ public-health/services/diseases/2019-novel-coronavirus-infection. html?topic =tilelink

10. Government of Canada. Government of Canada [internet]. COVID-19 status; 2020 June 10 [cited 2020 June 11]. Available from: https://covid-19-status.ca

11. Hartnett KP, Kite-Powell A, DeVies J, Coletta MA, Boehmer TK, Adjemian J, et al. Impact of the COVID-19 pandemic on emergency department visits: united states, January 1, 2019 - May 30, 2020. CDC MMWR Morb Mortal Wkly Rep. 2020;69(23):699-704.

12. Morley C, Unwin M, Peterson GM, Stankovich J, Kinsman L. Emergency department crowding: a systematic review of causes, consequences and solutions. PLoS ONE. 2018;13(8):e0203316. 